\title{
ORIGINAL
}

ARTICLES

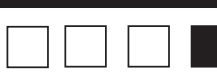

\section{Impact of a Targeted Rural and Underserved Track on Medical Student Match Into Family Medicine and Other Needed Workforce Specialties}

Kimberly Kardonsky, MD; David V. Evans, MD; Jay Erickson, MD; Amanda Kost, MD, MEd

\begin{abstract}
BACKGROUND AND OBJECTIVES: There is a shortage of physicians in rural communities in the United States. More than other types of primary care physicians, family physicians are the foundation for care in rural areas. ${ }^{1}$ There are also critical shortages of other specialties such as general surgery, pediatrics, internal medicine, and psychiatry in rural America. ${ }^{2-7}$ This study assessed student participation in the University of Washington School of Medicine's (UWSOM) Targeted Rural Underserved Track (TRUST) program as a predictor for family medicine (FM) and needed workforce specialty residency match.
\end{abstract}

\begin{abstract}
METHODS: The study group was 156 medical students from 2009-2014; 102 were accepted to the TRUST program compared to a control group of 54 who were not accepted into the TRUST program but did matriculate to UWSOM. Student characteristics for the two groups were compared using $t$ tests. Logistic regression analysis determined whether acceptance in TRUST predicted the outcomes measures of FM residency match or residency match into a needed rural physician workforce specialty; $t$ tests compared match rates to family medicine for TRUST applicants and graduates, UWSOM graduates, and US allopathic seniors.
\end{abstract}

RESULTS: TRUST program graduates had the same FM residency match rate and match rate in needed workforce specialties as the control group. The FM match rate for TRUST graduates was $29.1 \%$ compared to UWSOM at $16.9 \%$ and US seniors at $8.7 \%(P<.001)$.

CONCLUSIONS: Although match rates in FM and needed workforce specialties were not different in accepted versus not accepted groups, all TRUST applicants had an FM match rate that approaches $30 \%$, which is higher than the general UWSOM class and the United States. In order to help reach the goal of $25 \%$ of medical students matching into FM by 2030 , medical schools should consider having a rural program and using rural-focused admissions widely.

(Fam Med. 2021;53(2):111-7.)

doi: 10.22454/FamMed.2021.351484

7 he shortage of primary care providers in the United States is magnified in rural areas. ${ }^{1}$ Although $19.3 \%$ of the US population lives in rural areas, ${ }^{8}$ only about $11 \%$ of physicians work in rural settings. ${ }^{9}$ The demand for rural physicians is likely to grow as the rural work force ages and approaches retirement. ${ }^{10}$ More women are becoming physicians, and they are less likely to choose rural practice compared to their male counterparts. ${ }^{11,12}$ The percentage of elderly people is higher in rural communities, creating a greater need for more chronic disease management, specifically increasing the need for primary care. ${ }^{13}$

This is not a new issue. A century ago, medical training shifted from small dispersed programs to an urban university-based system, contributing to a rise of medical specialization and the decline of generalist practice. ${ }^{14}$ More recently, established schools increased their class size and new medical schools opened with the hope that this would fill the primary care gap and doctors would filter out to rural communities. ${ }^{15}$ Despite these changes, student interest in rural practice continues to steadily decline. ${ }^{9,16,17}$ Multiple medical schools have tried to ameliorate the problem of waning interest in rural practice through various strategies including targeted admissions for students likely to practice rurally, early and consistent exposure to rural practice, and financial incentives. ${ }^{18-23}$ While family medicine is the foundation of care for people in rural areas, ${ }^{9}$ there are also shortages in other specialties including pediatrics, internal medicine, general surgery and psychiatry. ${ }^{2-7}$

To address the physician shortages present in the rural areas in the Washington, Wyoming, Alaska, Montana and Idaho (WWAMI) region, the University of Washington School

From the University of Washington School of Medicine (Drs Kardonsky, Evans, Erickson and Kost). 
of Medicine created the Targeted Rural Underserved Track (TRUST) program in $2008 .{ }^{24}$ TRUST begins with a targeted admissions process that preferentially admits students from rural areas or with substantial rural experience. All students are sent information on the TRUST program with the UWSOM secondary application. TRUST applicants are required to complete a specific secondary application that addresses rural connections and practice interests. Applicants are invited to specific interviews that focus on these rural attributes. Once admitted, TRUST scholars participate in a longitudinal curriculum connected to a single rural continuity site, the TRUST continuity community (TCC). Students begin TRUST with a 1- to 2-week "First Summer Experience," during which they spend time in their TCC to learn about the clinic and community prior to starting medical school. They continue to return to their continuity rural site during their 18-month preclinical curriculum including a month-long summer experience with the Rural Underserved Opportunities Program (RUOP) between first and second year. During the clinical phase, they stay in their TCC for an 18-24 week longitudinal clinical rotation. The TRUST program includes multiple other components such as mentorship and educational and informal social experiences that have been previously described (Figure 1). ${ }^{24}$

The TRUST program began in 2008. Therefore, it is too soon to determine if it is meeting its goal of creating physicians who practice in rural communities. This study compared match rates into family medicine residencies and needed workforce specialties for graduates who were accepted into TRUST with those who applied to TRUST and were not accepted, but matriculated to UWSOM via general admissions. It also compares the match rate into family medicine for TRUST applicants to UWSOM and to US allopathic seniors from 2013-2018. Since interest in rural practice is associate with higher FM match rates, we hypothesized that TRUST graduates would match to FM at higher rates than graduates who did not participate in TRUST. A power analysis for the included graduates indicated that sample size would permit detection of a $20 \%$ point difference in FM match rate from TRUST graduates above the historical UWSOM FM match rate of approximately $17 \%$.

\section{Methods}

\section{Subjects and Settings}

One hundred fifty-six students applied for TRUST and matriculated into UWSOM between 2009 and 2014 and were included in this study. Of these, three withdrew from medical school and 11 have not graduated, for a total sample size of 142 . At the time that these data were obtained in 2018, the UWSOM was the only allopathic medical school for the five-state region of Washington, Wyoming, Alaska, Montana, and Idaho. UWSOM currently enrolls 270 students per year, but during the 2009-2014 time frame, 220 students were enrolled from 2009-2012, 235 in 2013, and 240 in 2014. Students obtain preclinical education at one of six regional campuses and then experience required and elective clerkships in communities across the five states. TRUST began in Montana and expanded to all WWAMI states. ${ }^{24}$ Now each state enrolls students including incoming slots of three in Wyoming, 10 in Washington, two in Alaska, 12 in Montana, and seven in Idaho.

\section{Data Sources}

The UWSOM Office of Admissions provided data on whether students applied to and were accepted or not into the TRUST program. The TRUST program provided data on whether students participated in a summer Rural Underserved Opportunities Program (RUOP) or the Family Medicine Interest Group (FMIG), define as ever attending an FMIG event. This data set was given to the Department of Bioinformatics and Medical Education to link with demographic data (age, sex, race/ethnicity, underrepresented background, rural background, disadvantaged background) and responses to an internally administered matriculation survey called the Biographical and Career Preferences Inventory (BCPI) and the residency specialty for each student. Biographical data collected were categorical and included the highest level of education obtained by family members, employment of family members, number of siblings, and state and size of community the student grew up in, including distance and accessibility to nearest metropolitan area. Career preferences at medical school entry were rated on a 5-point Likert-type scale ( $1=$ strongly avoid, to $5=$ strongly inclined), including 28 medical specialties, 32 items about level of specialization, practice setting, insurance payment models, and types of medical problems seen, and 23 items about preferred geographic setting of practice. Language background was measured with four categorical items about first language spoken, age at which English was first spoken, primary household language, and language known best. Finally, career plans at matriculation were assessed using three open-ended spaces in which students were asked to write in their top choice of medical specialties, their certainty of those choices using a 5-point rating scale, and their rating of 13 descriptions of practice attributes. The Department of Family Medicine provided match rates into family medicine for the graduating classes from 20132018. We obtained national match rates into family medicine from the American Academy of Family Physicians website. ${ }^{25}$ The Department of Bioinformatics and Medical Education linked all data and returned a deidentified dataset for analysis.

\section{Variables}

This study had three main outcomes. Two outcome variables were dummy coded: match to a family medicine residency and match to a needed workforce specialty (family medicine, 
Figure 1: UWSOM Targeted Rural/Underserved Track

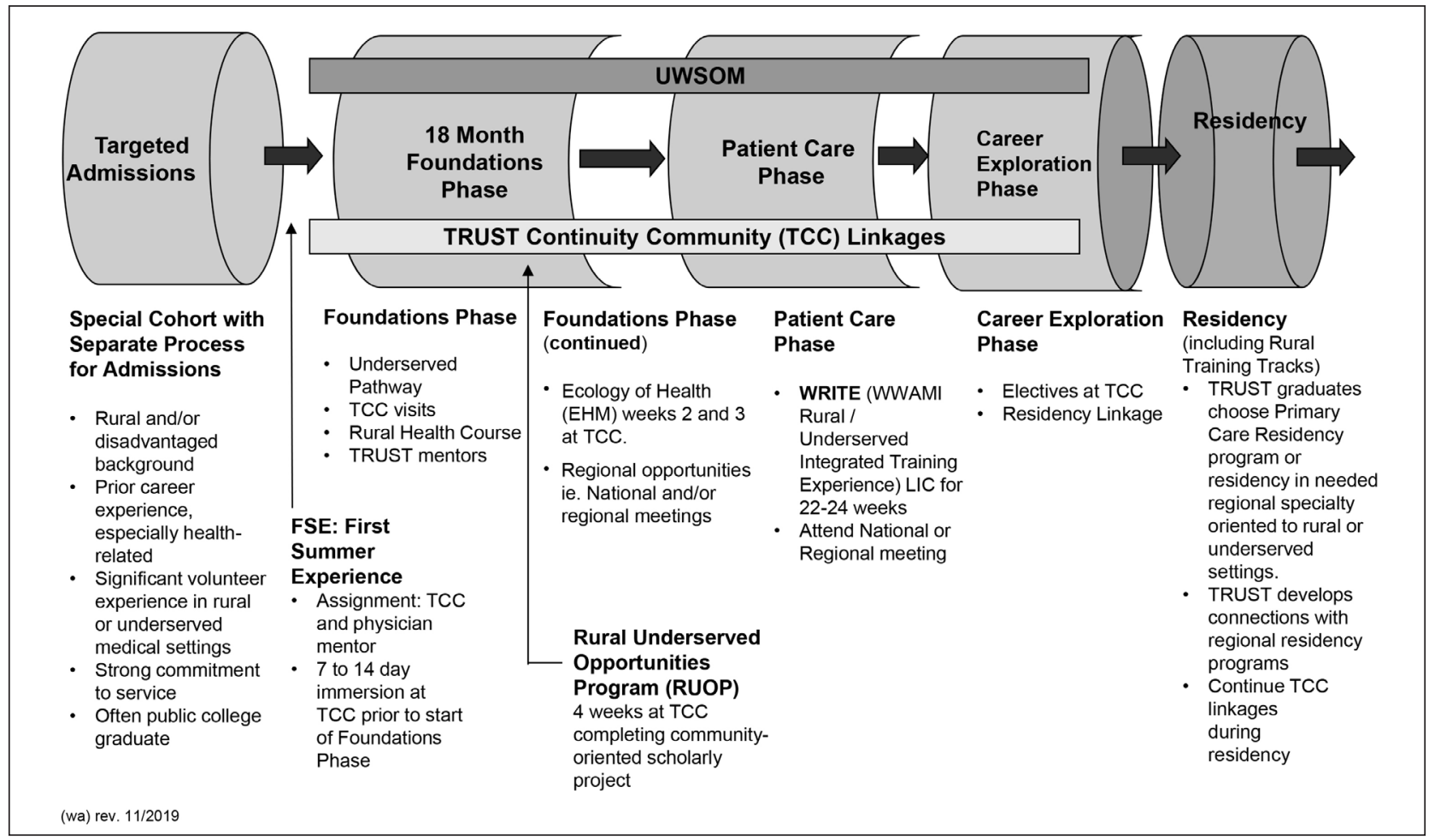

internal medicine, pediatrics, psychiatry, and general surgery). The independent variable was whether a student was accepted into and completed the TRUST program. Covariables included demographic data and composite variables from the BCPI, summarized in (Table 1). The third outcome variable was percentage of TRUST graduates, UWSOM graduates, and US seniors matching to family medicine for each year between 2013 and 2018.

\section{Analysis}

To determine if TRUST participation was resulting in a cohort of different students, we used $t$ tests and $\chi^{2}$ to compare students accepted into TRUST (study group) versus students not accepted into TRUST but accepted into UWSOM (control group) on demographic and interest variables (Table 1). We calculated descriptive statistics of the outcome measures of family medicine match and target specialty match. Given the small number of subjects, and to avoid inclusion of spurious variables not included a priori that might over-specify the regression models, we used exploratory $t$ test and $c^{2}$ tests to examine each variable by the two outcome measures. We retained variables if they showed association with a $P$ value of less than .2 , to avoid an $80 \%$ chance of including spurious variables. We used logistic regression with standard prediction entry to determine which of the identified variables of interest in (Table 1) uniquely predicted each of the first two outcome measures using standard predictor entry. We set $\alpha$ at .05 for significance for all analyses performed using SPSS version 25 (IBM Corporation, Armonk, NY). We compared the third outcome variable of family medicine match for TRUST graduates, UWSOM graduates, and US seniors using $t$ tests. The Human Subjects Division at the University of Washington approved this study.

\section{Results}

Table 2 shows characteristics and match outcomes for the study group compared to the control group. Compared to control group, those who were accepted into the TRUST program were less likely to be from a community that was near an urban center (within 50 miles; $39 \%$ vs $69 \%, P<.001)$, or had high accessibility to an urban center (39\% vs $62 \%, P<.008)$. Accepted students reported lower interest in practicing in communities with high urban accessibility compared to control group students (3.56 vs $4.12 P=.005$ ), lower interest in specialty practice ( $2.60 \mathrm{vs}$ $2.81, P=.03)$ and academic practice ( 2.78 vs $3.18, P=.08$ ).

The only variable that significantly predicted match into family medicine for students who applied to the TRUST program was if the student listed family medicine as their top specialty choice upon matriculation to medical schools. Students who reported family medicine as their top specialty choice had an odds ratio of 5.14 (95\% CI 1.87-14.14) compared to students who listed another specialty. Demographic characteristics, other career preferences at matriculation, and participation in medical school programs did not predict match to family medicine (Table 3 ).

The only variable that significantly predicted match into targeted specialties for students who applied to the TRUST program was 
Table 1: Variable Descriptions

\begin{tabular}{|c|c|c|}
\hline Variable & Description & Type \\
\hline Age & $\begin{array}{l}\text { Measured in years by subtracting the year of the student's } \\
\text { residency match from their year of birth }\end{array}$ & Continuous \\
\hline Sex & Dichotomized as male or female ( $1=$ female $0=$ otherwise $)$ & Binary \\
\hline Rural background & $\begin{array}{l}\text { Dichotomized indicating whether a student reported rural } \\
\text { background, (1=yes, } 0=\text { otherwise })\end{array}$ & Binary \\
\hline Disadvantaged background & $\begin{array}{l}\text { Dichotomized indicating whether a student reported disadvantaged } \\
\text { background, or receipt of federal or state assistance (1=yes, } \\
0=\text { otherwise) }\end{array}$ & Binary \\
\hline English language learner & $\begin{array}{l}\text { Dichotomized into whether the student spoke English as a second } \\
\text { language at any time during childhood ( } 1=\text { English language } \\
\text { learner, } 0=\text { native English speaker) }\end{array}$ & Binary \\
\hline Low maternal education & $\begin{array}{l}\text { Dichotomized to maternal education of high school or below } \\
\text { (1=high school or below, } 0=\text { all others) }\end{array}$ & Binary \\
\hline Physician parent & Dichotomized to any parent who is a physician $(1=$ physician, $0=$ no $)$ & Binary \\
\hline Primary care interest & Mean interest in internal medicine, pediatrics, and primary care & Continuous \\
\hline Specialty care interest & Mean interest of 30 specialties and tertiary care & Continuous \\
\hline Size of home community & Ever lived in a community less than 50,000 (1=yes, $0=$ no) & Binary \\
\hline Urban accessible home community & $\begin{array}{l}\text { Ever lived in a community that is very accessible to urban area } \\
(1=\text { yes, } 0=\text { no })\end{array}$ & Binary \\
\hline Urban distance home community & $\begin{array}{l}\text { Ever lived in a community that is within } 50 \text { miles of an urban } \\
\text { area }(1=\text { yes, } 0=\text { no })\end{array}$ & Binary \\
\hline Interest in small community practice & Mean interest in practicing in a community of less than 50,000 & Continuous \\
\hline $\begin{array}{l}\text { Interest in urban accessible } \\
\text { community }\end{array}$ & $\begin{array}{l}\text { Mean interest in practicing in a community that is very accessible } \\
\text { to urban area }\end{array}$ & Continuous \\
\hline $\begin{array}{l}\text { Interest community practice close to } \\
\text { urban area }\end{array}$ & $\begin{array}{l}\text { Mean interest in practicing in a community that is within } 50 \text { miles } \\
\text { of urban area }\end{array}$ & Continuous \\
\hline Academic practice interest & $\begin{array}{l}\text { Mean of interest on a 5-point rating scale across three items: basic } \\
\text { science, research interest, clinical science in medical school }\end{array}$ & Continuous \\
\hline Rural practice interest & $\begin{array}{l}\text { Mean of rating of interest in rural care and desire to live in rural } \\
\text { area }\end{array}$ & Continuous \\
\hline
\end{tabular}

if the student had a physician parent (Table 4). Students who had a physician parent had a odds ratio of 6.14 (95\% CI 1.13-33.41) of entering targeted specialties compared to those without a physician parent. No other variables significantly predicted entry into targeted specialties by TRUST graduates or those who applied to but were not accepted into TRUST, including other demographics, career preferences, and participation in TRUST or FMIG.

Both UWSOM graduates and applicants to the TRUST program match to family medicine at higher rates than the national average (Table 5). From 2013-2018, 29.1\% of TRUST applicants matched to family medicine, compared to $16.9 \%$ of
UWSOM graduates $(P<0.01)$, compared to $8.7 \%$ nationally $(P<.01)$.

\section{Discussion}

While the ultimate goal of the TRUST program enhancing the rural physician workforce in the WWAMI region cannot yet be assessed, this study highlights several important findings. Students who participated in the TRUST program as well as students who applied and were not accepted into the program but did matriculate to UWSOM all entered into residencies for family medicine and needed workforce specialties at the same rate. All students who applied to the TRUST program, whether they participated in TRUST or not, selected family medicine at a higher rate than the UWSOM and
US allopathic medical students as a whole. ${ }^{25}$ The main association for family medicine match was stated interest in family medicine. The TRUST application process selected for students who were more likely to have rural ties and were less likely to have an interest in specialty care and academic medicine. ${ }^{25,26}$

The 29.1\% FM match for all TRUST applicants far exceed both the UWSOM and national averages. Family physicians provide $42 \%$ of the care in rural areas and thus having a medical student admission process that results in close to $30 \%$ of graduates entering FM is a critical in the creation a rural physician workforce. ${ }^{27}$ Approximately 20\% of family medicine residency graduates will go on to practice in rural areas. ${ }^{28}$ 
Table 2: TRUST Not Accepted vs Accepted

\begin{tabular}{|c|c|c|c|c|c|}
\hline \multirow{3}{*}{ Variable } & \multicolumn{5}{|c|}{ TRUST Applicants } \\
\hline & \multicolumn{2}{|c|}{$\begin{array}{c}\text { Not Accepted } \\
n=54 \\
n=48 \text { (Match) }\end{array}$} & \multicolumn{2}{|c|}{$\begin{array}{c}\text { Accepted } \\
n=102 \\
n=94 \text { (Match) }\end{array}$} & \multirow{2}{*}{$\begin{array}{c}\text { Not Accepted } \\
\text { vs Accepted }\end{array}$} \\
\hline & $\mathbf{M}$ & (SEM) & M & (SEM) & \\
\hline Age in years & 29.61 & 0.44 & 30.03 & 0.46 & .57 \\
\hline Sex & 0.54 & 0.07 & 0.57 & 0.05 & .71 \\
\hline Rural background & 0.07 & 0.04 & 0.16 & 0.04 & .14 \\
\hline English language learner & 0.19 & 0.05 & 0.10 & 0.03 & .12 \\
\hline Disadvantaged background & 0.24 & 0.06 & 0.27 & 0.04 & .65 \\
\hline Low maternal education & 0.15 & 0.05 & 0.20 & 0.04 & .43 \\
\hline Physician parent & 0.11 & 0.04 & 0.11 & 0.03 & .95 \\
\hline Size of home community & 0.17 & 0.05 & 0.24 & 0.04 & .32 \\
\hline Urban accessibility of home community & 0.62 & 0.07 & 0.39 & 0.05 & .008 \\
\hline Distance of home from urban area & 0.69 & 0.07 & 0.39 & 0.05 & .001 \\
\hline Interest in small community practice & 3.48 & 0.13 & 3.63 & 0.08 & .33 \\
\hline Interest in high urban accessible practice & 4.12 & 0.14 & 3.56 & 0.12 & .005 \\
\hline Interest in practice close to urban area & 3.84 & 0.16 & 3.45 & 0.13 & .06 \\
\hline Rural interest & 4.15 & 0.14 & 4.20 & 0.11 & .79 \\
\hline Specialty interest & 2.81 & 0.07 & 2.60 & 0.06 & .03 \\
\hline Primary care interest & 3.84 & 0.12 & 3.75 & 0.09 & .56 \\
\hline Family medicine first & 0.41 & 0.07 & 0.45 & 0.05 & .60 \\
\hline Academic interest & 3.18 & 0.11 & 2.78 & 0.08 & .003 \\
\hline Family medicine match & 0.27 & 0.06 & 0.32 & 0.05 & .47 \\
\hline Target specialties match & 0.54 & .07 & 0.64 & 0.05 & .22 \\
\hline
\end{tabular}

This investigation confirms prior studies that show initial interest in family medicine and certain demographics, including rural intentions or rural upbringing, strongly influence choice of family medicine. ${ }^{29-31}$ Rural upbringing and plans for FM are key factors for ultimate rural practice. ${ }^{23}$

This study has both strengths and limitations. One strength is a wellmatched control group that minimizes selection bias since it is composed of students who applied to the TRUST program and were not enrolled in TRUST but who did matriculate to UWSOM outside of TRUST. Other studies have explored family medicine match or targeted specialty match, but a recent systematic review did not identify any studies that compare outcomes of graduates that were and were not accepted into a rural program..$^{32}$ Another strength is the number of variables explored.
Limitations of this study include the small number of participants, that resulted in low power and the ability to only detect a 20 percentage point increase in FM match. Another limitation is the use of residency match data as a proxy outcome measure for rural practice. A limited number of people apply to the TRUST program and the number of slots for TRUST participants is finite. During the early years of TRUST, the admissions process and the program elements continued to evolve into what is now a mature program. In the past few years, the admissions team has a clearer picture of what a successful TRUST cohort entails and are admitting individuals that are a suitable fit. The UWSOM has a unique structure, including an admissions process that takes place in six locations across the five states, therefore results may not be generalizable to other schools. It is also plausible that students who were not admitted to the TRUST program could have pursued experiences that closely align with the participants like rural rotations, rural mentors, and similar rural curriculum beyond what could be formally measured. It could be that just by having a rural-focussed program at a school has a ripple effect in the medical education community at large. This is an area to explore in the future after more TRUST applicants and participants graduate and are established in practice.

Based on this study, the characteristics of medical students and what they bring upon matriculation is of great significance. Family medicine leaders and policy makers should evaluate processes that support the $25 \times 2030$ family medicine goal, an initiative led by the AAFP that encompasses several FM organizations and strives to have $25 \%$ of 
Table 3: Predictors of FM Match

\begin{tabular}{|l|c|c|c|c|c|c|}
\hline \multicolumn{1}{|c|}{ Coefficient } & b & (SE) & \multirow{2}{*}{$\boldsymbol{P}$} & \multicolumn{2}{c|}{ OR } & \multicolumn{2}{c|}{ 95\% CI for OR } \\
\cline { 3 - 7 } & & & & & LB & UB \\
\hline TRUST accepted & -0.25 & 0.52 & .63 & 0.78 & 0.28 & 2.16 \\
\hline Family medicine first & $\mathbf{1 . 6 4}$ & $\mathbf{0 . 5 2}$ & $\mathbf{. 0 0}$ & $\mathbf{5 . 1 4}$ & $\mathbf{1 . 8 7}$ & $\mathbf{1 4 . 1 4}$ \\
\hline Specialty Interest & -0.38 & 0.44 & .39 & 0.68 & 0.29 & 1.63 \\
\hline Low maternal education & -1.71 & 0.92 & .06 & 0.18 & 0.03 & 1.09 \\
\hline Plan to practice in urban accessible community & -0.11 & 0.24 & .65 & 0.90 & 0.57 & 1.43 \\
\hline $\begin{array}{l}\text { Plan to practice in community close to urban } \\
\text { area }\end{array}$ & -0.36 & 0.23 & .11 & 0.70 & 0.45 & 1.09 \\
\hline Distance of home from urban area & -0.39 & 0.49 & .43 & 0.68 & 0.26 & 1.76 \\
\hline Plan for academic practice & -0.44 & 0.32 & .17 & 0.65 & 0.34 & 1.21 \\
\hline FMIG participant & 0.04 & 0.55 & .94 & 1.04 & 0.36 & 3.05 \\
\hline Constant & 2.68 & 1.52 & .08 & 14.62 & & \\
\hline
\end{tabular}

Abbreviations: TRUST, Targeted Rural Underserved Track program; FMIG, Family Medicine Interest Group; LB, lower bound; UB, upper bound. $\mathrm{N}=129$. Model fit $\chi^{2}(9)=35.67, P<.01$, pseudo- $\mathrm{R}^{2} 0.34$.

Table 4: Predictors of Entering Target Specialties

\begin{tabular}{|l|c|c|c|c|c|c|}
\hline \multicolumn{1}{|c|}{ Coefficient } & \multirow{2}{*}{ bw } & \multirow{2}{*}{ (SE) } & \multirow{2}{*}{$\boldsymbol{P}$} & \multirow{2}{*}{ OR } & \multicolumn{2}{c|}{ 95\% CI for OR } \\
\cline { 3 - 7 } & & & & & LB & UB \\
\hline TRUST Accepted & 0.35 & 0.46 & .46 & 1.41 & 0.57 & 3.51 \\
\hline Sex & 0.67 & 0.45 & .14 & 1.95 & 0.81 & 4.70 \\
\hline Rural background & -0.22 & 0.62 & .72 & 0.80 & 0.24 & 2.69 \\
\hline Disadvantaged background & -0.17 & 0.48 & .72 & 0.84 & 0.33 & 2.18 \\
\hline Family medicine first & 0.51 & 0.47 & .28 & 1.66 & 0.66 & 4.17 \\
\hline Specialty interest & -0.90 & 0.50 & .07 & 0.41 & 0.15 & 1.08 \\
\hline Low maternal education & -0.77 & 0.62 & .21 & 0.46 & 0.14 & 1.56 \\
\hline Physician parent & $\mathbf{1 . 8 2}$ & $\mathbf{0 . 8 6}$ & $\mathbf{. 0 4}$ & $\mathbf{6 . 1 4}$ & $\mathbf{1 . 1 3}$ & $\mathbf{3 3 . 4 1}$ \\
\hline Interest in practice close to urban area & 0.05 & 0.18 & .79 & 1.05 & 0.74 & 1.48 \\
\hline Rural interest & -0.27 & 0.21 & .20 & 0.76 & 0.50 & 1.16 \\
\hline Academic practice interest & -0.53 & 0.30 & .08 & 0.59 & 0.33 & 1.06 \\
\hline FMIG participant & 1.10 & 0.58 & .06 & 2.99 & 0.96 & 9.35 \\
\hline Constant & 4.38 & 1.96 & .03 & 80.14 & & \\
\hline
\end{tabular}

Abbreviations: TRUST, Targeted Rural Underserved Track program; FMIG, Family Medicine Interest Group; LB, lower bound; UB, upper bound. $\mathrm{N}=132$. Model fit $\chi^{2}(12)=35.67, P<.01$, pseudo- $\mathrm{R}^{2} 0.35$.

Table 5: Percentage of Graduates Matching to Family Medicine by Year for UWSOM, TRUST, and Nationally

\begin{tabular}{|l|c|c|c|}
\hline \multirow{2}{*}{ Graduating Year } & \multicolumn{2}{|c|}{ Percentage Matching to Family Medicine } \\
\cline { 2 - 4 } & UWSOM & TRUST & National \\
\hline 2013 & 16.8 & 12.5 & 8.3 \\
\hline 2015 & 18.1 & 28 & 8.6 \\
\hline 2016 & 15.7 & 36.4 & 8.4 \\
\hline 2017 & 16.3 & 28.6 & 8.7 \\
\hline 2018 & 17 & 43.3 & 8.8 \\
\hline Mean (SD) & 17.5 & 25.7 & 9.3 \\
\hline
\end{tabular}

Abbreviations: UWSOM, University of Washington School of Medicine; TRUST, Targeted Rural Underserved Track program. $P<.01$ for UWSOM vs TRUST and for National vs TRUST. 
US medical school seniors choose FM as their specialty by the year $2030 .{ }^{33}$ By having a rural-focused program at a medical school, there is a pull for students with rural ties to apply and match into family medicine at a high rate. Holistic admission criteria that encompasses rural background/ experience or rural attributes as a positive weight, in addition to items like GPA and MCAT scores should be considered widely at medical schools seeking to increase the percentage of their graduates matching to family medicine.

PRESENTATIONS: This study was presented as "Do You TRUST There are Ways to Have Students Choose Family Medicine and Other Needed Specialties for Rural Areas?" at the Society of Teachers of Family Medicine Conference on Medical Student Education in Portland, Oregon, January 31, 2020.

CORRESPONDING AUTHOR: Address correspondence to Dr Kimberly Kardonsky, Health Sciences Center (E-304), Box 356390, Seattle, WA 98195. 206-543-9425. Fax: 206-543-3821. kardok2@uw.edu.

\section{References}

1. Kuehn BM. Reports warn of primary care shortages. JAMA. 2008;300(16):1872-1875, 1874-1875. doi:10.1001/jama.300.16.1872.

2. Petterson SM, Phillips RLJ Jr, Bazemore AW, Koinis GT. Unequal distribution of the U.S. primary care workforce. Am Fam Physician. 2013;87(11). https://www.aafp.org/ afp/2013/0601/od1.htm.

3. MacDowell M, Glasser M, Fitts M, Nielsen K, Hunsaker M. A national view of rural health workforce issues in the USA. Rural Remote Health. 2010;10(3):1531.

4. Rosenblatt RAHL. Book culture and medicine. West J Med. 2000;173(5):348-351. doi:10.1136/ ewjm.173.5.348.

5. Larson EH, Andrilla CHAGLA. Supply and Distribution of the Primary Care Workforce in Rural America. 2019;2020(June):1-10.

6. Puls MW. Shortage of Rural Surgeons: How Bad is it? Bulletin of the American College of Surgeons. https://bulletin.facs.org/2018/04/ shortage-of-rural-surgeons-how-bad-is-it/. Published April 1, 2018. Accessed September 28, 2020.

7. Ellis AR, Konrad TR, Thomas KC, Morrissey JP. County-level estimates of mental health professional supply in the United States. Psychiatr Serv. 2009;60(10):1315-1322. doi:10.1176/ ps.2009.60.10.1315.

8. United States Census Bureau. 2010 Census Urban and Rural Classification and Urban Area Criteria. https://www.census.gov/programs-surveys/geography/guidance/geo-areas/ urban-rural/2010-urban-rural.html. Revised December 2, 2019. Accessed September 28, 2020.
9. Rosenblatt RA, Chen FM, Lishner DM, Doescher MP. The Future of Family Medicine and Implications for Rural Primary Care Physician Supply. Seattle, WA: WWAMI Rural Health Research Center; 2010. http://depts.washington. edu/uwrhrc/uploads/RHRC_FR125_Rosenblatt. pdf.

10. Dall T, Reynolds R, Jones K, Chakrabarti R, Iacobucci W. The complexities of physician supply and demand. Assoc Am Med Coll. 2019. https:// aamc-black.global.ssl.fastly.net/production/media/filer_public/31/13/3113ee5c-a038-4c16-89af294a69826650/2019_update_-_the_complexities_of_physician_supply_and_demand_-_projections_from_2017-2032.pdf.

11. Chen F, Fordyce M, Andes S, Hart LG. Physicians ? A 15-Year Update. 2010;85(4):594-598

12 Doescher MP, Ellsbury KE, Hart LG The distribution of rural female generalist physicians in the United States. J Rural Health. 2000;16(2):111-118. doi:10.1111/j.1748-0361.2000.tb00444.x

13. National Rural Health Association. Elder Health in Rural America. https://www.ruralhealthweb.org/getattachment/Advocate/ Policy-Documents/ElderHealthinRuralAmericaFeb2013.pdf.aspx.

14. Duffy TP. The Flexner Report-100 years later Yale J Biol Med. 2011;84(3):269-276.

15. Association of American Medical Colleges. Results of the 2018 Medical School Enrollment Survey. Cent Work Stud. Published July 2019.

16. Rabinowitz HK, Diamond JJ, Markham FW, Rabinowitz C. Long-term retention of graduates from a program to increase the supply of rural family physicians. Acad Med. 2005;80(8):728-732. doi:10.1097/00001888200508000-00004.

17. Shipman SA, Wendling A, Jones KC, KovarGough I, Orlowski JM, Phillips J. The decline in rural medical students: a growing gap in geographic diversity threatens the rural physician workforce. Health Aff (Millwood). 2019;38(12):2011-2018. doi:10.1377/ hlthaff.2019.00924.

18. Rabinowitz HK, Diamond JJ, Markham FW, Wortman JR. Medical School Programs to Increase the Rural Physician Supply: A Systematic Review and Projected Impact of Widespread Replication. https://journals. lww.com/academicmedicine. doi:10.1097/ ACM.0b013e318163789b.

19. Pathman DE. What outcomes should we expect from programs that pay physicians'training expenses in exchange for service? N C Med J. 2006;67(1):77-82

20. Wendling AL, Phillips J, Short W, Fahey C, Mavis $\mathrm{B}$. Thirty years training rural physicians outcomes from the Michigan State University College of Human Medicine Rural Physician Program. Acad Med. 2016;91(1):113-119. doi:10.1097/ACM.0000000000000885.

21. Zink T, Center B, Finstad D, et al. Efforts to graduate more primary care physicians and physicians who will practice in rural areas: examining outcomes from the university of Minnesota-duluth and the rural physician associate program. Acad Med. 2010;85(4):599604. doi:10.1097/ACM.0b013e3181d2b537.
22. Mareck DG. Federal and state initiatives to recruit physicians to rural areas. Virtual Mentor. 2011;13(5):304-309. doi:10.1001/virtualmentor.2011.13.5.pfor1-1105.

23. Fuglestad A, Prunuske J, Regal R, Hunter C, Boulger J, Prunuske A. Rural family medicine outcomes at the University of Minnesota Medical School Duluth. Fam Med. 2017;49(5):388393

24. Greer T, Kost A, Evans DV, et al. The WWAMI Targeted Rural Underserved Track (TRUST) program: an innovative response to rural physician workforce shortages. Acad Med. 2016;91(1):65-69. doi:10.1097/ ACM.0000000000000807.

25. American Academy of Family Physicians. 2020 Match ${ }^{\circledR}$ Results for Family Medicine. https:// www.aafp.org/medical-school-residency/program-directors/nrmp.html. Accessed September 29, 2020.

26. Rabinowitz HK, Diamond JJ, Markham FW, Paynter NP. Critical Factors for Designing Programs to Increase the Supply and Retention of Rural Primary Care Physicians. JAMA. 2001;286(9):1041-1048. doi:10.1001/jama.286.9.1041.

27. Agency for Healthcare Research and Quality. The Distribution of the U.S. Primary Care Workforce. Rockville, MD: AHRQ; 2018. https:// www.ahrq.gov/research/findings/factsheets/primary/pcwork3/index.html. Accessed October 3, 2019.

28. Colwill JM, Cultice JM. (2003). The future supply of family physicians: implications for rural America. Health Affairs. 2003;22(1). https://doi. org/10.1377/hlthaff.22.1.190.

29. Kost A, Evans D, Dobie S, Sanders E. What is the impact of the underserved pathway program on graduates entering an underserved family medicine residency? five-year findings from the University of Washington school of medicine. Acad Med. 2018;93(7):1042-1047. doi:10.1097/ACM.0000000000002073.

30. Gill H, McLeod S, Duerksen K, Szafran O. Factors influencing medical students' choice of family medicine: effects of rural versus urban background. Can Fam Physician. 2012;58(11):e649-e657.

31. Senf JH, Campos-Outcalt D, Kutob R. Factors related to the choice of family medicine: a reassessment and literature review. J Am Board Fam Pract. 2003;16(6):502-512. doi:10.3122/ jabfm.16.6.502.

32. Goodfellow A, Ulloa JG, Dowling PT, et al. Predictors of primary care physician practice location in underserved urban or rural areas in the United States: A systematic literature review. Acad Med. 2016;91(9):1313-1321. doi:10.1097/ ACM.0000000000001203.

33. Porter S. AAFP Hosts Launch of $25 \times 2030$ Student Choice Collaborative. American Academy of Family Physicians. https:// www.aafp.org/news/education-professionaldevelopment/20180905twentyfiveby2030.html. Accessed September 28, 2020. 